\title{
Dádiva na Gestão de Unidades de Conservação: Um estudo sobre a Participação de Conselheiros do Mosaico Veredas-Peruaçu, Brasil
}

\section{Gift in the Management of Protected Areas: A Study about Participation of Directors Mosaic Veredas-Peruaçu, Brazil}

\author{
Rodrigo Burkowski ${ }^{1}$, Ana Alice Vilas Boas ${ }^{2}$ \\ ${ }^{1}$ Universidade Federal de Ouro Preto, Rua Diogo de Vasconcellos, Ouro Preto - Minas Gerais, 35400000, Brasil. \\ 2Universidade Federal de Lavras, Departamento de Administração e Economia, Campus Universitário, Lavras - Minas Gerais, 37200000, Brasil.
}

Resumo: Em 2002, surge os Conselhos dos Mosaicos de Unidades de Conservação na área ambiental. Esta instância visa unir esforços e dinamizar a gestão integrada de áreas protegidas. Este trabalho apresenta os resultados de dois anos de criação do Mosaico Veredas-Peruaçu. Por meio de análise de conteúdo das Atas, observação participante e entrevista semiestruturada, discute-se o funcionamento do conselho e a "doação" dos membros. Os dados apontam que o conselho é uma esfera de participação institucionalizada e que a Dádiva está presente. O trabalho amplia as possibilidades de uso do paradigma da dádiva como lente para compreensão da realidade socioambiental brasileira.

Palavras-Chave: Democracia, Doação, Gestão Compartilhada.

Abstract: The Boards of Mosaics of Conservation was created in 2002 for the environmental area. This body aims to unite efforts and streamline the integrated management of protected areas. This paper presents the results of two years of creating the Mosaico Veredas-Peruaçu. Through content analysis of the minutes, participant observation and semi-structured interview, we discuss the functioning of the board and the "donation" of members. The data indicate that the board is a sphere of institutionalized participation and that the donation is present. The work expands the possibilities for use of the gift paradigm as lens to understand the social and environmental reality in Brazil.

Key-Words: Democracy, Giving, Sharing Management.

Texto completo em português: http://www.apgs.ufv.br Full text in Portuguese: http://www.apgs.ufv.br

\section{INTRODUÇÃO}

O universo de transformações ocorridas nos últimos vinte anos na sociedade brasileira, em especial aquelas que impactam diretamente a conservação da natureza, têm gerado intensos debates no meio acadêmico e social. Sob o ponto de vista financeiro, no que tange a relação homem $X$ natureza, pode-se delinear alguns cenários, dentre eles há supremacia dos interesses econômicos sobre os sociais, levando a uma pressão pela flexibilização da legislação ambiental, sobretudo em regiões com baixo índice populacional. Dessa forma, utilizando-se de meios (i)lícitos se obtêm autorização para exploração de recursos madeireiros, extração mineral, expansão da agropecuária entre outras formas de destruição da floresta.

O discurso utilitarista que sustenta esse processo é que a floresta por si só não possui valor ou que seu valor não é passível de conversão em moeda corrente. Dessa forma, impõe-se um modelo economicamente insustentável e socialmente prejudicial, pois não permite a inclusão e socialização dos benefícios gerados por esses mesmos recursos. Dessa forma, nota-se que existe a necessidade de se (re)discutir o modelo de desenvolvimento proposto para o país e especial para as áreas protegidas. Esse processo, além de impor uma reflexão sobre as formas de gestão das Unidades de Conservação, deve, necessariamente, envolver a sociedade como um todo.

De acordo com o Sistema Nacional de Unidades de Conservação - SNUC -, existem dois grupos de unidades de conservação: Unidades de Proteção Integral e Unidades de Uso Sustentável. A regra geral é que as Unidades de Uso Sustentável são obrigadas a constituírem conselhos consultivos ou deliberativos, ao passo que as Unidades de Proteção Integral devem, obrigatoriamente, dispor de um Conselho Consultivo. Os conselhos gestores de unidades de conservação são, portanto, um desses instrumentos jurídico-administrativos utilizados pelo Estado para permitir a participação popular nos processos de gestão de unidades de conservação. Espaços democráticos e, portanto, de conflito, que entende-se ser uma das características essenciais da democracia moderna.

É possível afirmar que pouco se sabe a respeito do funcionamento institucional, político e normativo de conselhos de gestão de Unidades de Conservação. A primeira avaliação de efetividade de gestão das UC's apontou que 125 de 245 Unidades de Conservação pesquisadas têm desempenho inferior a $40 \%$. O

Correspondência/Correspondence: Rodrigo Burkowski, Universidade Federal de Ouro Preto, Rua Diogo de Vasconcellos, Ouro Preto - Minas Gerais, 35400000, Brasil.

rodrigo@turismo.ufop.br 
segundo ciclo de avaliação aponta melhoras, mas 91 das 291 Unidades pesquisadas apresentam baixa efetividade de gestão. (ICMbio, 2011)

Araújo (2007) realizou uma interessante revisão sobre o tema e apresentando os modelos de gestão de Unidades de Conservação. Os modelos estão alinhados com a gestão gerencial/ estratégica aplicada ao meio ambiente, pois para ele "os modelos de excelência são usados para apresentar o mais alto nível, o estado da arte de como organizar e gerir instituições" Araújo (2007, p.189). Entende-se que apesar da importância deste modelo de gestão, sua aplicação em Unidades de Conservação deve ser feita à luz das experiências participativas, cujos sentidos vão além da dinâmica econômica. Após amplo e exaustivo levantamento documental realizado por Novick e Souza (2010), revelou-se que a produção científica sobre os Conselhos de Meio Ambiente no Brasil, nas três esferas federadas, é escassa e incipiente, limitada a 27 estudos, refletindo a pouca valorização, em geral, social, e, em particular, acadêmica, relacionada a esses espaços. Por fim, considerando as diretrizes de gestão participativa propostas pelo SNUC e seus decretos posteriores, as análises produzidas por Cohen (2007) indicam que os órgãos dos governos responsáveis vêm tomando iniciativas para estabelecer uma gestão mais participativa, por meio de Conselhos Consultivos, apesar das diversas falhas no processo.

No presente artigo, buscou-se compreender e interpretar a atuação dos sujeitos na cogestão das Unidades de Conservação que compõem o mosaico Veredas-Peruaçu, em especial aqueles que possuem vínculos com Parque Nacional Grande Sertão Veredas (PNGSV) e com a Reserva Estadual de Desenvolvimento Sustentável Veredas do Acari (REDSVA), que são áreas de proteção integral e de uso sustentável respectivamente.

$O$ trabalho tem assim, como objetivo principal, analisar a natureza da relação entre a manifestação da Dádiva e a Democracia Deliberativa dos conselheiros em um Mosaico de Unidades de Conservação. Além deste, propõe-se: 1) Contribuir para valorizar a Dádiva como recurso metodológico nas Ciências Sociais 2) Discutir, à luz das experiências dos sujeitos participantes e representados nas reuniões, a importância da "Doação" para o conselho na gestão da UC's; 3) Relacionar o sentido da participação à Teoria da Dádiva.

\section{A Dádiva}

O uso de modelos nas ciências sociais visa simplificar ao mesmo tempo em que torna tangível determinado fenômenos que se apresentam em espaço $X$ tempo distintos. A tentativa de se criar um modelo e sistematizar a dádiva é uma ideia que Mauss e alguns de seus seguidores não aceitam com certa facilidade. Como exemplo dessa tentativa têm-se o "Mapa Conceitual de Práticas do Dom" de Vandevelde (2000). Os autores contrários a essa sistematização, visto as restrições que impõe ao Dom, são favoráveis a um desenvolvimento mais geral do paradigma do Dom e preferem continuar a se apoiar nas categorias de Mauss e focar em diferentes graus e suas várias combinações de interesse e desinteresse, liberdade e obrigação. Caillé (1998) ao defender este ponto de vista teórico, sua importância relativa para diferentes sociedades, considera relevante focar em cada uma das obrigações de Mauss, que também seria uma variável cultural. (Silber, 2006, p. 41).

Para facilitar o entendimento e aprofundar algumas questões, divide-se essa prática em três momentos (DAR, RECEBER e RETRIBUIR) e com isso se cria novas categorias para sua análise. A primeira delas são as motivações para DAR. Essa análise do ponto de vista do doador permite distinguir alguns tipos, tais como a acidental ou não planejada, que seria aquele "Dar" influenciado pelo desejo de garantir certa estabilidade aos pares, mas não a transmissão de herança ou fortunas; O "Dar" voluntário que permite ser analisado em diversas categorias indo do mais puro altruísmo ao mais pessoal; $\mathrm{O}$ "Dar" das empresas que veem sendo muito utilizado pelas estratégias de responsabilidade social empresarial.

O segundo é a análise sob a ótica do Beneficiário do Dom. Será que ele vai ser grato ou, pelo contrário, humilhado? Qual é a natureza exata da obrigação de gratidão? Qual é o fundamento da distinção entre direitos e favores ou entre a justiça e a generosidade? Pode agradecimentos e contradons simbólicos ser suficiente para responder a um Dom material? Mesmo que o elemento surpresa seja essencial na escolha do contradom, isso não impede que todo o processo seja um jogo com regras que podem ser facilmente explicitadas. Godbout (1992) ao relatar exemplos sobre essa questão chama a atenção para a etimologia da palavra "obrigado". Para o autor, "podemos considerar a palavra "obrigado" como uma espécie de elipse para dizer que o fato de se receber um presente pode nos tornar em certo sentido, dependentes, entregar-nos à mercê daquele que dá" Godbout (1992, p.16).

Uma terceira possibilidade é concentrar-se sobre o significado do Dom. Ao focar a atenção sobre essa etapa se corre alguns riscos, como por exemplo, ceder às teorias da escolha racional e concluir que a Dádiva nada mais que do que uma troca instrumental, com objetivos e retornos bem estabelecidos. Pode-se extrair do "Ensaio sobre o Dom" (Mauss, 2003) que a maioria das práticas de dádiva tem algum interesse, eventualmente econômico, envolvido. Contudo, é ressaltado que o tipo de interesse não é igual a compreensão de interesse defendida pela racionalidade instrumental econômica.

\section{A Dádiva como Teoria ou Teoria da Dádiva}

Não é raro encontrar o termo "Teoria da Dádiva" associado à produção acadêmica que utiliza este referencial. Essa proliferação exige dos pesquisadores um maior rigor no seu uso a fim de evitar sua banalização. Godbout (1992, p.279) questiona sobre qual seria o caminho para "explicar teoricamente um fenômeno que tem tantas características aparentemente opostas a toda a formalização: livre, contextual, espontâneo, recusando a distinção sujeito-objeto no centro do pensamento moderno, sem regras de funcionamento explícitas?". Ou como teorizar sobre a Dádiva? 
A primeira questão que se impõe é a de se considerar a Dádiva dentro da perspectiva positivista ou não-positivista, ou melhor, quais seriam os critérios de demarcação (Popper, 2008) aceitos para sua compreensão. A opção, nas ciências sociais, por métodos e técnicas oriundas das ciências naturais, impede que a primeira construa seus próprios horizontes. Nesse sentido, o predomínio do positivo dentro das ciências sociais corroboraria para a validação daquilo que Levi-Strauss (apud Caillé, 1998, p.5) caracterizou como categorias nativas de alma ou de "espírito da coisa dada".

Segundo Alencar (1999), desde os anos 1930 o positivismo tem dominado as ciências sociais e só a partir dos anos 1960 as abordagens interpretativas começam a ganhar espaço no meio acadêmico. O positivismo, segundo Alencar (1999), estaria baseado em três ideias: a identificação de leis universais, a geração do conhecimento se restringe à experimentação e toda pesquisa científica tem os mesmos princípios metodológicos.

No caso da Dádiva, a abordagem positivista apresenta alguns problemas pois "a pretensão em descrever a dádiva - para nós que estabelecemos a distinção entre um sujeito e um objeto contém todas as armadilhas possíveis" (Casajus, 2008, p.77). O Hau, ou a Alma do objeto descrito pelo Ranapiri, um dos exemplos analisados por Mauss (2003) para construir sua Teoria da Dádiva, apresenta essas contradições.

Nesta perspectiva há a impossibilidade de distinguir quem é o sujeito e quem é o objeto a ser investigado, pois o objeto carrega consigo parte do sujeito e para Godbout (1998) e Mauss (2003) oferecer alguma coisa a alguém é oferecer alguma coisa de si. Para Reinhardt (2006) a fórmula de Mauss, que afirma haver mais nas trocas do que as coisas trocadas, indica que o ato de permuta deve ser compreendido, simultaneamente, enquanto signo e objeto a que este signo se refere. "A teoria da dádiva abre a possibilidade de uma teoria da significação apta a apreender a dimensão imanente e indéxica, ou seja, eficaz e causal, das trocas comunicativas, saindo-se assim do espectro dualista que ameaça as análises antropológicas do simbólico" (Reinhardt, 2006, p.5).

Para Constantino (2009), o uso do termo Hau - que significa alma - com a intenção de chamar a atenção para o aspecto moral essencial da dádiva, que é essa obrigação de restituir, fez com que Lévi-Strauss ignorasse a ênfase no exame delicado desta moral que Mauss pretendia dar ao longo do Ensaio, para logo acusá-lo de sucumbir ao misticismo nativo (Godbout, 1998). Cumpre lembrar que quando questionado sobre suas contribuições teóricas, Mauss (2003) afirmava, "Não estou interessado (...) em desenvolver teorias sistemáticas (...) Trabalho simplesmente com os meus materiais e se, ali ou acolá, aparece uma generalização válida, eu a estabeleço e passo a qualquer outra coisa." (Fournier, 1993, p.4).

Nesse contexto, para se aceitar uma Teoria da Dádiva é necessária uma mudança epistemológica e ontológica no e do investigador, ou como denomina Santos (2009) uma dupla ruptura. Dessa forma, as teorias de Mauss foram pioneiras, em expor a "objetividade" do humano, ou seja, a forma com que encontramos o outro e a nós mesmos nos objetos que nos cercam, como falamos através deles e como somos presos por seus vínculos, por seu espelhamento e por sua circulação, Reinhardt (2006). Para Constantino (2009), a Teoria da Dádiva conteria em seu cerne uma teoria da reciprocidade e uma teoria moral em estreita relação com o tema da solidariedade, completando, assim, o mapeamento das principais vertentes teóricas contemporâneas que se dedicam à releitura deste conceito-chave da Sociologia. Mas afinal, existe uma teoria da Dádiva?

Popper (2008, p.61) ensina que as teorias científicas são enunciados universais, ou de forma metafórica, "são redes, lançadas para capturar aquilo que denominamos "o mundo": para racionalizá-lo, explica-lo, dominá-lo", sendo o que se busca é estreitar cada vez mais essa teia. Na construção da Teoria da Dádiva, Reinhardt (2006) destaca a convergência de três aspectos centrais: a relação objeto/signo, a relação eu/outro e a relação sujeito/objeto. Dessa forma, considerando essa convergência, se poderia afirmar, apoiado em Martins (2010) e Godbout (2006) que apontam para uma dupla função da Dádiva, o qual seja: um fenômeno social e modelo para a compreensão do social que existe uma Teoria da Dádiva.

\section{Paradigma da Dádiva}

A construção de teorias está diretamente relacionada à aceitação ou não dos métodos empregados em sua construção. No caso dos paradigmas, sua validação também se dá pela aceitação ou refutação de seus fundamentos. Para Alencar (2003, p.24) ao eleger um paradigma como "o processo válido" de geração de conhecimento, "sentiu-se não ser mais necessário conhecer as bases filosóficas que o sustentam". Dessa forma, para o autor, ocorreu um distanciamento da filosofia da ciência e o método científico, o que levou a formação de gerações de cientistas sociais sem o devido conhecimento dos fundamentos do método científico.

O termo "paradigma" vem do grego paradeigma e significa, em sentido próprio, modelo ou exemplo. "Em seus múltiplos usos, pode ser empregado com acepção de algo que por sua exemplaridade deve ser imitado ou seguido, bem como com o significado de provar e demonstrar algo com a ajuda de outra coisa que serve de guia ou modelo" (Domingues, 2004, p.51).

Esse entendimento diverge da leitura de Khun (1998). Para este último, se por um lado paradigma indica toda a constelação de crenças, valores, técnicas, partilhadas pelos membros de uma comunidade determinada. De outro denota um tipo de elemento nessa constelação: a solução concreta de quebra-cabeças, que empregadas como modelos ou exemplos, podem substituir regras explicitas como base para a solução dos restantes quebra-cabeças da ciência normal (Khun, 1998).

No caso da Dádiva, para Constantino (2009, p.215) "Hoje em dia, inúmeros autores a tese da originalidade e do potencial heurístico, tardiamente descobertos, da obra de Mauss e, especialmente, de seu estudo sobre o dom ou a dádiva, bem como a emergência de um novo paradigma em ciências sociais.". 
Isto se deve, dentre outras coisas, pois sua contribuição foi suficientemente sem precedente, permitindo uma aglutinação e aceitação por diversos cientistas de seus insight.

\section{Metodologia de trabalho}

Este trabalho utiliza métodos qualitativos para analisar a natureza da relação entre a participação dos conselheiros e o agir dadivoso nas unidades de conservação. Dentre as técnica foi utilizada a pesquisa documental, com análise de conteúdo (Bardin, 1979) para compreender o atual estágio de institucionalização do conselho consultivo do Mosaico Veredas-Peruaçu, tendo como base as atas das reuniões. Outro método utilizado foi o Estudo de Caso. Yin (2001) afirma que o estudo de caso é uma inquirição empírica que investiga um fenômeno contemporâneo dentro de um contexto da vida real, quando a fronteira entre o fenômeno e o contexto não é claramente evidente e onde múltiplas fontes de evidência são utilizadas. Como técnica foi utilizada as narrativas de experiência, por meio do Discurso do Sujeito Coletivo (Lefèvre e Lefèvre, 2003). Para esta etapa, o pesquisador participou de todas as reuniões ordinárias que aconteceram no período da pesquisa compreendido entre o Julho de 2012 e Dezembro de 2012. Foram acompanhadas três reuniões do Conselho do Mosaico e três reuniões do Conselho do PNGS.

Para interação com os sujeitos, foi adotada a entrevista não-estruturada, que conforme Mattos (2005) é aquela em que é deixado ao entrevistado decidir-se pela forma de construir a resposta. Em um plano geral têm-se a predominância de homens, sendo que as mulheres representam um terço das entrevistas realizadas. As idades variam entre vinte e oito e sessenta e três anos, com concentração na faixa de trinta a quarenta anos. Todos possuem pelo menos o segundo grau completo e dois estão terminando o mestrado ou doutorado. Foram realizadas onze entrevistas presenciais, registradas com consentimento dos entrevistados. Quatro foram realizadas por email, pois não foi possível agendar as entrevistas presencialmente.

Para a análise, foi empregado o método de Análise do Discurso do Sujeito Coletivo. O DSC, desenvolvido por Lefèvre e Lefèvre (2003) ao final da década de 1990 é o foco deste, bem como os estudos na área da saúde como alternativa de enfrentamento dos problemas relativos à análise de corpus qualitativo e à análise quantitativa de pesquisa de opinião que findam por negligenciar a discursividade (Gondin e Fischer, 2009). O desafio que este método busca responder é o da expressão do pensamento ou opinião coletiva.

A opção de trabalhar com o DSC se deu por acreditar que por esta forma de análise se consegue atender melhor os objetivos deste trabalho, pois, como afirmam Gondim e Fischer (2009, p.14) "o discurso do sujeito coletivo é a junção dos discursos individuais, respeitando os sentidos e o nível de compartilhamento", o que acaba por dar maior credibilidade às informações prestadas, pois torna possível identificar o pensamento coletivo, o que de comum existe para o grupo estudado.

\section{Análise da Dádiva no CCMVP}

A análise do ciclo da Dádiva buscou evidenciar as categorias propostas por Caillé (2002) dentro das etapas apresentadas por Mauss (2003). Essa divisão em Dar-Receber-Retribuir é, como exposto anteriormente, uma separação didática, pois a dádiva é uma amálgama desse processo. Como aponta Godbout (1992, p.137) "é-se levado a considerar que os três momentos do ciclo dar, receber, retribuir - se confundem frequentemente: segundo o ponto de vista do ator, dar é retribuir, e vice-versa". A lógica estabelecida para análise partiu do princípio de que a sociedade doa (Dar) à organização o direito de representá-la no conselho consultivo. Esta por sua vez irá escolher um conselheiro para representá-la nas reuniões. É este conselheiro que irá dar a voz de seus representados nas reuniões. O "receber" por parte da organização envolve a indicação de um membro para que este represente a coletividade nas reuniões. E por fim, o "retribuir", que são os resultados das ações deste representante nas reuniões e seus desdobramentos.

A análise do Dar, que seria em tese o ponto zero do processo ou uma espécie de "posição original" (Rawls, 2009), visa compreender as razões pelas quais as entidades estão presentes no conselho. Como exposto anteriormente, este processo é dinâmico e optou-se por considerar este como o início do processo de circulação da Dádiva. O primeiro passo para o dar de si da sociedade para uma entidade e posteriormente para um indivíduo para então retornar à sociedade. Esse momento, que aqui se estabelece como o primeiro passo para a construção do circulo da Dádiva, é momento no qual a sociedade "Dá" a uma organização ou representante, a responsabilidade de representa-la no CCMVP.

As categorias são analisadas dentro deste contexto, na qual a "obrigação" é a possibilidade de recusa da dádiva, ou seja, a organização poderia não participar ou ter que participar incondicionalmente. A "liberdade" é neste caso reflexo desse agir, ou seja, o grau de constrangimento para participar é de tal ordem que a entidade e seu representante não podem abrir mão. O "interesse" por sua vez é o que Bourdier (1996) denomina "princípio da razão suficiente", na qual os sujeitos agem por alguma razão, mesmo que o comportamento razoável não seja racional. Por fim, o "desinteresse", que não é o ato gratuito, mas sim o agir cujas bases são fundadas em interesse não econômico e cujo fim não é um ganho material.

A obrigação em participar do conselho deve ser vista de forma relativa. Como observado por Vandenbergue (2004) a obrigação na dádiva é livre, mas ainda assim, coativa. Neste caso a ancoragem foi a "Obrigação institucional". O Discurso do Sujeito Coletivo é "Nós somos convidados a participar do Conselho. Existe um número limitado de cadeiras, mas até hoje não deu problema. Somos 44 conselheiros, mas nas reuniões aparecem pouco mais da metade. No caso dos órgãos públicos, os chefes das UC's são obrigados a participar, mas isso não quer dizer que eles não querem participar ou que querem. Algumas associações também são obrigadas a participar por terem projetos aprovados pelo CCMVP." 
Sendo assim, apesar de não ser imposta, é obrigatória, pelo menos do ponto de vista moral. A dádiva é livre porque pressupõe a espontaneidade do ego, sendo, entretanto, socialmente coativa. Conforme registrado nas Atas do CCMVP houve uma chamada pública para as entidades que tivessem interesse em participar deste conselho, manifestassem, por meio de ofício e outros documentos, sua intenção. Então, neste caso não houve uma doação no sentido estrito do termo. A cada dois anos acontece uma renovação e visa, dentre outras coisas, retirar do conselho aqueles membros que não comparecem as reuniões. Essa obrigação legal-formal, ou seja, o convite de membros apenas para compor o quadro, têm como resultado uma frequência média de 24 membros. Isto porque, apesar de haver um dispositivo regimental para substituição de membros em cada de 3 ausências consecutivas, este não foi utilizado deste a criação do conselho. Na região do Mosaico existem mais de 100 entidades na região que poderiam ter a obrigação de participar. Não houve concorrência para as cadeiras, pois há participação é livre, com exceção dos casos abaixo.

Em relação às 22 cadeiras das entidades do setor público, 11 pertencem as UC's que compõem o Mosaico e as outras estão distribuídas entre prefeituras e outros órgãos do governo federal e estadual. A crítica feita pelos entrevistados foi em relação à obrigação, no sentido legal do termo. Para Constantino (2009) é a relação transitória de direito, que nos constrange a dar, fazer ou não fazer alguma coisa economicamente apreciável, em proveito de alguém, que por ato nosso ou de alguém conosco juridicamente relacionado, ou em virtude da lei, adquiriu o direito de exigir de nós essa ação ou omissão. Obrigação é o vínculo jurídico pelo qual alguém se sujeita para com outrem a dar, a fazer ou não fazer.

No caso em tela, como observado nas reuniões, algumas prefeituras apresentaram grande ausência às reuniões, principalmente às reuniões que antecederam as eleições municipais. Por mais que estejam obrigados a participar das reuniões, os sujeitos representantes de alguns órgãos não se sentem impelidos a contribuir com o funcionamento deste órgão. Uma das hipóteses para essa situação é a falta de prestígio político ou reconhecimento do representante da organização, salvo quando a reunião é realizada em sua cidade. Como exposto por um entrevistado, "a sensação que tenho é que alguns senhores querem ocupar posição de destaque nas reuniões e nos grupos, sem se doar, sem ter contribuído antes." (entrevistado 3). Essa falta de reconhecimento dos pares e do sujeito para com o conselho pode levar ao desinteresse na participação. Apesar disso, outras prefeituras são bastante ativas, participam das reuniões, colocam recursos (financeiros e estrutura) para que as reuniões aconteçam em sua cidade, participam dos grupos de trabalho.

Ao relacionar essa ação específica com o agir proposto, percebe-se que há um afastamento da Dádiva porque a obrigatoriedade presente nesta é uma obrigação moral e não uma obrigação legal. Portanto, os indivíduos que não transcende da obrigação legal para a obrigação moral acabam por se afastar do conselho, apresentando faltas injustificadas, manifestando pouco ou nada nas reuniões. Por fim, a percepção geral dos entrevistados é que a participação da sua organização no conselho não é obrigatória, mas sua participação contribui para o desenvolvimento das atividades do Mosaico.

A liberdade do Dom não é resulta de um cálculo matemático, de ganhos e perdas. Dentro da perspectiva adotada, a entidade é livre para recusar o Dom e aquelas cuja presença é feita com base em um ato racional, no sentido em que calcula esses ganhos, procurando maximizar o seu poder, os seus interesses, torna-se um conselheiro indesejável. Bourdier (1996, p.1) considera que o caráter "primordial da experiência do dom é, sem dúvida, sua ambiguidade: de um lado, essa experiência é (ou pretende ser) vivida como rejeição do interesse, do cálculo egoísta, como exaltação da generosidade, do dom gratuito e sem retribuição." Godbout (2002) considera a melhor definição sociológica de mercado aquela que o define como um vínculo social que visa escapar às obrigações normais inerente aos vínculos sociais. Em síntese, a liberdade moderna é justamente a ausência de dívida. A análise da liberdade pode ser sintetizada na fala de um dos conselheiros que disse "no começo fui porque fomos intimados a ir. Como nossa atividade é importante na região, somos convidados para vários conselhos (...) hoje vou por prazer, pois a participação neste conselho acabou por facilitar meu trabalho". (Part.5).

Neste caso, a ancoragem foi a recusa à participação, sendo o DSC: "Temos a liberdade de ir ou não as reuniões. Fomos convidados ou pressionados a ir, mas posso, se quiser, não ir. Alguns estão lá obrigados e por isso não se sentem muito a vontade para se manifestar. Tem outros que não pode dar brecha que fala sem parar, acaba até prejudicando a reunião. É importante que os conselheiros se sintam a vontade para manifestar, sem medo de serem julgados. Também é importante que o próprio conselheiro respeite a opinião do outro."

Portanto, quando a organização tem liberdade para não participar, para recusar o Dom, mas ainda assim faz questão de se interar, é porque ocorreu uma transcendência entre a obrigação e a liberdade.

Uma das principais críticas ao paradigma adotado neste trabalho diz respeito a racionalidade instrumental-econômica. O discurso dominante busca justificar a ação e a mobilização de esforços com base no interesse econômico, nos fins específicos e resultantes da ação calculada. Os conselheiros foram unânimes em afirmar que a remuneração pela participação iria desvirtuar a função do conselho. A percepção é que o dinheiro, neste caso, é prejudicial para as relações que lá se estabelecem. A luz do paradigma adotado tem-se que o dinheiro anula o Dom, pois seria um equivalente simbólico que neutraliza a relação desigual que se estabelece na Dádiva. Com visto, a Dádiva é círculo cujo um membro sempre está em posição inferior ao outro e só irá ser superior ao retribuir com algo de valor simbólico maior que o recebido. Neste caso, com a remuneração, não haveria isso. 
Neste caso a ancoragem para o interesse no Dar foi justamente a remuneração. O DSC é "Receber para participar das reuniões não dá certo. As pessoas irão estar lá por causa do dinheiro e não para contribuir. É importante que quem participa das reuniões esteja com interesse em contribuir com algo maior, com a comunidade que ele representa, com a sociedade como um todo. Se tiver dinheiro à coisa complica. Mas deve ter ajuda de custo e a pessoa não pode pagar para ir. Senão desestimula também. Pagar para trabalhar não dá."

Como evidenciado por Latouche (2006), a conduta virtuosa, que consiste em unir o interesse pessoal ao interesse geral, reside apenas na sociabilidade e não é senão o resultado de um cálculo que, sozinho, permite distinguir entre o verdadeiro interesse e o interesse cego, sendo que essa comunidade de interesse entre iguais é o fundamento do tratado de aliança perpétua que concretiza o estado da sociedade.

Por outro lado, a percepção que se teve durante as reuniões e a análise da entrevista, é que existe, também, um interesse econômico em estar presente no conselho, pois "estar presente no conselho abre portas" (Entrevistado 01). Outro entrevistado deixa claro que, como o projeto passou pelo conselho, foi o conselho que permitiu ter acesso aos recursos, por isso vale apena participar. Por fim, extrai-se das leituras do material bibliográfico e do acompanhamento das reuniões, que existe a valorização do cerrado, apesar da Amazônia ser o foco na questão ambiental, o que acaba por facilitar o acesso a recursos nacionais $e$ internacionais. Dessa forma, concordando com Godbout(1992) seria ingenuidade dos pesquisadores concluir que não existe interesse econômico na ação dos sujeitos presentes as reuniões. Outrossim, pode-se afirmar com segurança que os interesses coletivos e a doação dos pares para a coletividade superam os eventuais interesses individuais, contribuindo para o agir dadivoso.

O desinteresse dentro desta primeira etapa da dádiva foi evidenciado por meio do entendimento que os participantes tinham em relação ao reconhecimento das capacidades e limitações dos pares. Como relatado pelos entrevistados, a participação voluntária neste conselho gera novos vínculos e fortalece alguns já existentes, além de resgatar eventuais laços que foram rompidos. Como relatou o entrevistado 3, "antes eu conhecia, sabia quem era "fulano", hoje, vou na casa dele, tomo café e se precisar posso até dormir.". Acredita-se que os entrevistados enxerguem em seus pares, pessoas de boa intenção e independente de ser da parte de gestão, fiscalização, educação, podem contribuir para melhorar a sua comunidade. Como exposto anteriormente, com o desinteresse espontâneo se fazem amigos, casamentos, etc., mas não a economia de mercado ou o Estado.

O desinteresse teve como ancoragem o aprendizado é produziu o seguinte DSC "O conselho tem, efetivamente, 3 anos de atividade. Somos um conselho jovem, em uma região com poucos recursos. Como temos vários tipos de pessoas no grupo, é importante ter paciência, ir aprendendo, vendo quando posso falar, onde posso contribuir. Os conselheiros ajudam muito uns aos outros. Veja o caso das brigadas de combate a incêndio. $O$ pessoal do Parque tem torre de observação e acaba ajudando as outras unidades. Os índios também não estão formalmente no conselho mas estão participando, tentando ver como podem ajudar a fortalecer a região. Outro aspecto interessante é a amizade que surge entre os conselheiros e entidades. Temos vários projetos e parcerias que nascem dentro das reuniões do conselho. As vezes, do ponto de vista pessoal, não concordo com o caminho que está sendo escolhido, mas como foi o grupo que escolheu, devo aceitar."

Os assuntos que são debatidos em plenária são bem abrangentes. Discuti-se sobre combate a incêndio, caça, uso público, plantação, entre outros. A produção de consenso entre os pares é um dos objetivos do conselho, pois como lembra Rochlitz (2005, p.98) "são válidas as normas com as quais todas as pessoas envolvidas, como participantes racionais e mutuamente desinteressadas do processo político de escolha de princípios de justiça, concordariam, após discussão”. Dessa forma, o desinteresse dos conselheiros acaba por auxiliar na produção desses consensos e tendo como consequência, a manutenção das atividades do conselho.

\section{CONCLUSÃO}

O trabalho teve assim, como objetivo principal, analisar a natureza da relação entre a manifestação da Dádiva e a Democracia Deliberativa dos conselheiros em um Mosaico de Unidades de Conservação. Além deste, propôs-se contribuir para a análise da institucionalização da gestão participativa no Mosaico; Discutir, à luz das experiências dos sujeitos participantes e representados nas reuniões, a importância do conselho na gestão da UC's e relacionar o sentido da participação à Teoria da Dádiva;

Dentre os diversos métodos utilizados, destaca-se o Discurso do Sujeito Coletivo que teve como objetivo a síntese de depoimentos, e procurou revelar as opiniões, significados e posicionamentos dos sujeitos com mais nitidez sobre um determinado tema. O Discurso do Sujeito Coletivo busca revelar a representação social de um grupo sobre assuntos que estão imersos na coletividade e podem ser captados pelos discursos individuais.

A racionalidade comunicativa e a democracia deliberativa, estruturam-se em relação às ideias que moldam este mundo e que chegam ao sujeito a partir das experiências de sua prática. Estas não são um somatório de ações isoladas, fragmentos do social, mas um processo através do qual o sujeito se constrói e se expressa, no dinamismo de um concreto, que assim se faz. Dessa forma, o uso dessa técnica permitiu desvelar estruturas simbólicas que indicam a presença da Dádiva no Conselho Consultivo do Mosaico Veredas Peruaçu.

Retornando as suposições apresentadas na introdução do artigo, pode-se concluir que (i) há diferenças entre os participantes de conselhos deliberativos e conselhos consultivos. No caso do primeiro, como manifestado pelos entrevistados, os interesses econômicos influenciam mais o comportamento dos conselheiros, levando a um acirramento dos ânimos em algumas situações. 
Contudo, como estes mesmos entrevistados relataram, isto não é um problema em si, mas uma condição que deve ser trabalhada, e na medida em que o grupo evolui, os laços são fortalecidos, os consensos são produzidos, dessa forma, percebe-se que o agir não difere, de maneira significativa para o conselho consultivo.

No que se refere a proposta de ação Dadivosa, pelas características dos entrevistados, (ii) não há diferença no que se refere à reflexividade dos sujeitos. Ou seja, a atuação é muito parecida em todos os conselhos, existindo a obrigação, o interesse, o desinteresse e a liberdade.

Por fim o Conselho do Mosaico não é uma sobreposição de esferas de participação (iii). Na visão dos entrevistados são esferas distintas, com agendas distintas e necessárias para o desenvolvimento da região. Essa instância consultiva, pela área de abrangência e dinâmica de trabalho, contribui para novos laços e facilita o relacionamento entre os interessados na melhoria da qualidade de vida dos moradores do Sertão.

E finalizando têm-se o seguinte DSC "É bom participar dessas coisas, a gente conhece outras pessoas, outros pontos de vista. Ficamos sabendo de coisas novas. O conselho possui uma estrutura fixa, regida por um decreto federal que disciplina seu funcionamento básico. A rotatividade de membros é uma coisa boa e pelo regimento deve ser feita a cada dois anos. Muitas organizações são obrigadas a estarem no conselho, mas apesar disso alguns participam pouco das reuniões. Então aquelas que estão indo, estão fazendo porque gostam, porque querem contribuir e não por um interesse econômico direto. Se formos ver, das 44 entidades que compõem o conselho, três possuem interesse econômico direto na atuação do conselho. Mas apesar disso, estão lá para ajudar, contribuir. Participar também é bom para criar novas amizades, conhecer problemas e buscar soluções conjuntas. As vezes, um problema que acontece na minha unidade ou organização acontece na do vizinho ou em outro conselho que participo. Assim, muitas cabeças pensando ajuda a encontrar a solução. Outra coisa importante são as amizades que surgem no conselho. Hoje conheço mais gente e mais gente me conhece, isso facilita o trabalho de todo mundo. Dá trabalho, mas é bom."

\section{REFERÊNCIAS}

Alencar, E. (2003). Pesquisa social e monografia. Lavras: UFLA/ FAEPE.

Araujo, M. A. R. (2007). Unidade de Conservação no Brasil: da república à gestão de classe mundial. Belo Horizonte: SEGRAC.

Bardin, L. (1979). Análise de conteúdo. Lisboa: Edições70.

Brasil. (2006) lei $n^{\circ} 11.284$, de 2 de março de 2006. Recuperado de http://www.planalto.gov.br/ccivil_03/_ato2004-2006/2006/lei/l11284.htm.

Brasil. (2010). Ministério do meio ambiente - secreataria executiva fundo nacional do meio ambiente. Termo de referência fnma $n^{\circ}$ 01/2010.

Bourdieu, P. (1996). Algumas notas adicionais sobre o dom. Mana, v. 2, n. 2, 7-20.

Caillé, A. (1998) nem holismo nem individualismo metodológicos: marce mauss e o paradigma da dádiva. Rev. bras. Ci. Soc. 13(38), 5-38 Recuperado de http://www.scielo.br/scielo.php? script=sci_arttext\&pid=s0102-69091998000300001\&lng=pt\&nrm=iso. doi: 10.1590/S0102-69091998000300001

Casajus, D. (1984). L énigme de la troisième personne article paru dans différences, valeurs, hiérarchie. Textes offerts à louis dumont, jean-claude galley (dir.), Éditions de I' école des hautes étudesen sciences sociales,
65-78.

Recuperado

de

http://www.academia.edu/1189849/lenigme_de_la_troisieme_personne.

Cohen, M. (2007). Avaliação do uso de estratégias colaborativas na gestão de unidades de conservação do tipo parque na cidade do rio de janeiro. (Tese de doutorado), ufrrj, rio de janeiro.

Constantino, A. K. (2009). Solidariedade: entre o desencanto e o reencanto (Tese). Campinas, SP.

Domingues, I. (2004). Epistemologia das ciências sociais: tomo i positivismo e hermeneutica - durkheim e weber. São paulo: edições loyola.

Durkheim, E. (1971). As regras do método sociológico. São paulo: companhia editora nacional.

Funatura. (2008). Relatório de cumprimento do objeto parcial - rco. Projeto mosaico sertão veredas-peruaçu.MMA/fnma -106/2005. Brasília, df.

Funatura. (2010). Implementação do plano de desenvolvimento territorial de base conservacionista do mosaico sertão veredas - peruaçú. Brasil.

Freitas, A. S. (2005). Fundamentos para uma sociologia crítica da formação humana: um estudo sobre o papel das redes associacionistas (Tese). Recife, PE.

Fournier, M. (1993). Marcel mauss ou a dádiva de si. Revista brasileira de ciências sociais, São Paulo, n. 21, 104-112.

Godbout, J. T. (1992). O espírito da dádiva. Lisboa: Instituto Piaget epistemologia e sociedade.

Godbout, J. T. (2002) homo donator versus homo oeconomicus. In martins, paulo henrique (org.). A dádiva entre os modernos: discussão sobre os fundamentos e as regras do social. Petrópolis RJ: vozes.

Gondim, S. E. M. G., \& Fischer, T. (2009). O discurso, a análise de discurso e a metodologia do sujeito coletivo na gestão intercultural. Cadernos gestão social, 2, (1), 09-26. Salvador.

Icmbio (2011). Instituto chico mendes de conservação da biodiversidade. Avaliação comparada das aplicações do método rappam nas unidades de conservação federais, nos ciclos 2005 e 2010. Brasil. Brasília: Icmbio.

Khun, T. S. (1998). A estrutura das revoluções científicas. São paulo: perspectiva.

Latouche, S. Le veau d'or est vainqueur de dieu. Essai sur la religion de l'économiein caillé, alain. De l'anti-utilitarisme anniversaire, bilan et controverses. $\mathrm{R}$ e $v \mathrm{u}$ e d $\mathrm{u}$ ma uss. s e m e s t $r$ i e I I e. $\mathrm{N}^{\circ} 27$ premier semestre 2006.

Lefèvre, F., \& Lefevre, A. M. (2003). O discurso do sujeito coletivo. Um novo enfoque em pesquisa qualitativa (desdobramentos). Caxias do sul, rs: educs, 2003

Martins, P. H. (2002). A dádiva entre os modernos: discussão sobre os fundamentos e as regras do social. Petrópolis, editora vozes.

Mauss, M. Ensaios de sociologia. São paulo: perspectiva, 2003.

Novicki, V., \& Souza, D. B. (2010). Políticas públicas de educação ambiental e a atuação dos conselhos de meio ambiente no brasil: perspectivas desafios. Ensaio: aval.pol.públ.Educ, 18 (69).

Pinheiro, M. R. (2010) recomendações para reconhecimento e implementação de mosaicos de áreas protegidas. Brasília, DF, gtz.

Popper, K. (2007). A lógica da pesquisa científica. Trad. I. hegenberg \& O. S. Mota. São paulo: Cultrix.

Rawls, J. (2009). Uma teoria da justiça. São paulo: Martins Fontes.

Reinhardt, B. M. N. (2006). A dádiva da teoria: epistemologia e reciprocidade no circuito do "dado" antropológico. Campos - Revista de antropologia social da universidade federal do paraná, $7(1)$. Recuperado de http://ojs.c3sl.ufpr.br/ojs2/index.php/campos/article/view/5431/3998

Rochlitz, R. (2005). Habermas: o uso público da razão. Rio de janeiro: Tempo brasileiro, 2005.

Santos, B. S. (org.) (2009). Democratizar a democracia. Rio de janeiro: editora civilização brasileira.

Silber, I. (2006). Sortilèges et paradoxes du don. Introduction à la traduction en hébreu de l'essai sur le don de marcel mauss. In caillé, alain. De l'anti-utilitarisme anniversaire, bilan et controverses. $R$ e $v$ u e d u ma uss. $s$ e mestrie // e. $\mathrm{N}^{\circ} 27$.

Snuc. (2000). Lei $n^{\circ}$ 9985/00, (2000) sistema nacional de unidades de conservação. Constituição da república federativa do brasil. Brasília.

Triviños, A. N. S. (1987). Introdução à pesquisa em ciências sociais: a pesquisa qualitativa em educação. São paulo: atlas.

Vandenberghe, F. (2004). Desvendando marx: o marxismo e o fim da sociedade do trabalho. In P. H. Martins \&, B. Nunes (Orgs.). A nova ordem social. Perspectivas da solidariedade contemporânea. Brasília: paralelo 15.

Vandevelde, A. (sous la dir. de) (2000). Gifts and interests. Peeters, Louvain.

\section{Agradecimentos}

Os autores agradecem à FAPEMIG pelo apoio no desenvolvimento de parte deste trabalho. 